\title{
Occupation-Based Hand Therapy in South Africa: Challenges and Opportunities
}

\author{
Susan de Klerk, B OT (SU), DHT (UP), M OT (SU) \\ Lecturer, Division of Occupational Therapy, Department of Interdisciplinary Health Sciences, Stellenbosch University
}

Elretha Badenhorst, B OT (SU)

Occupational Therapist, Therapy in Action

Amy Buttle, B Sc OT (UCT)

Senior Occupational Therapist, Tygerberg Hospital

Fairuz Mohammed, B Sc OT (UWC)

Occupational therapist, Private Practice, Panorama Medi-Clinic

Jeanette Oberem, Sc OT (UCT)

Occupational therapist, Private practice

Occupation-based hand therapy (OBHT) is an approach to practice that integrates multiple frames of reference, while remaining rooted in an occupational therapy perspective. There are a number of benefits and challenges that have been recognised in hand therapy settings. The use of an occupation-based approach in the field of hand therapy is of interest to all occupational therapists practising in this field. This commentary explores the challenges and opportunities of OBHT as an approach in the assessment and treatment of clients with hand conditions in the South African context. The authors describe OBHT, explore the barriers in practice and propose guidelines for such an approach in our context. Recommendations are made to enhance the understanding and practice of an OBHT approach in everyday hand therapy practice within South Africa.

Key words: Occupation-Based Hand Therapy, Client Centred practice

\section{INTRODUCTION}

Occupational therapy services for clients with hand conditions aim to restore and rehabilitate the primary tool of function; the hand. Hand function is important for participation in daily occupations and in most cases requires a specialised treatment approach'. In South Africa, three universities offer post-graduate qualifications in the field of hand therapy towards fostering and developing the specialised skills required in this field.

The South African Society of Hand Therapists (SASHT) defines hand therapy as:

"...the art and science of rehabilitation of the upper limb - from the shoulder to the hand. Hand therapy assists a person to regain maximum use of his or her upper limb after injury, surgery or the onset of disease. Hand therapists treat with exercises and activities, apply modalities and create custom-made splints to help the hand heal and protect it from additional injury. Although the physical treatment entails treatment of the upper limb, emphasis is placed on reintegration into the work place, activities of daily living and leisure time pursuits."

Occupational therapy beliefs and theory advocate the use of occupation as a means to an end and an end in itself ${ }^{3}$. In addition, occupational therapists employ biomechanical approaches in order to achieve treatment goals ${ }^{4}$. A balance in occupational therapy intervention can be achieved when considering the dynamics as outlined in the International Classification of Functioning, Disability and Health (ICF) $)^{5}$ (Figure I).

The ICF considers the person together with her/his health condition within a specific environment, influenced by contributing factors that emanate from inside and outside the particular indi-

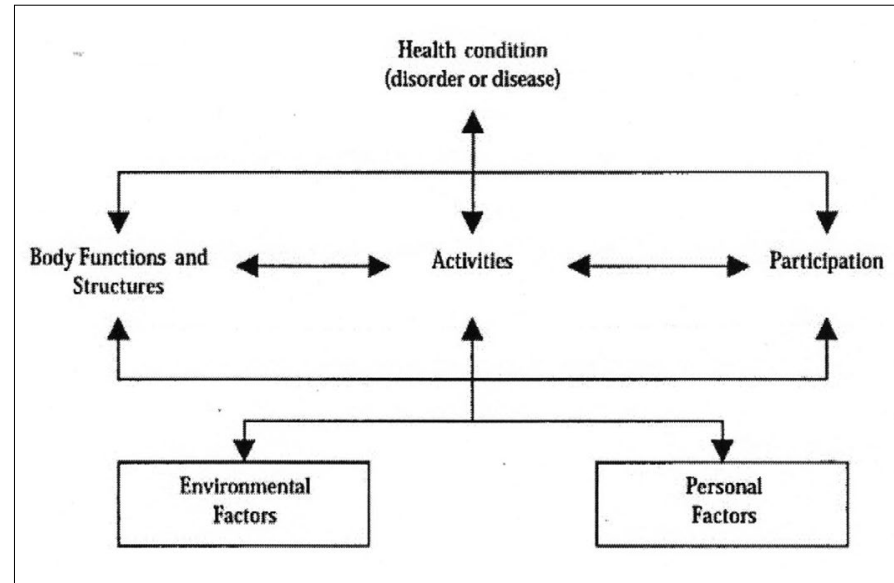

Figure I: International Classification of Functioning, Disability and Health

vidual. The "inside factors" comprise those from the body, mind and what the ICF calls the "personal factors" 6 . The health condition in question in this commentary comprises some pathology/disorder of the upper limb affecting body function and structure, for example range of motion and muscle strength, associated with restrictions in activity and participation, for example the ability to brush your teeth or participate in the realms of work and leisure. In Figure I above, "activities" is central and the arrows "point in both directions" indicating a dynamic relationship between the health condition (together with body structure and function) and activities; and 
by virtue of similar interaction between activities and participation. Participation in real-life activities in the different realms of human endeavour also influences/affects the health condition (and body structure and function $)^{5}$.

In occupational therapy all components of the ICF framework (Figure I) have to be considered and addressed, more or less at the same time during assessment and treatment. The person must be viewed through a sound and detailed understanding of their activity limitations and participation restrictions. For this, an occupation-based approach to hand therapy should be adopted. Amini ${ }^{7,8}$ describes an occupation-based approach to hand therapy as a balance between the significance of occupation as a treatment modality and the use of biomechanical approaches and principles. An occupation-based approach does not negate the role and impact of the biomechanical frame of reference, but rather promotes the use of occupation as a framework within which biomechanical approaches should be applied ${ }^{6}$. This client-centred approach should however be grounded in a sound knowledge of and insight into anatomy, patho-physiology and biomechanics. However, it seems that the primary focus of current occupational therapy assessment and treatment for these clients, remains on body structure and function ${ }^{1,4}$. This is also true in South Africa' ${ }^{9}$. Occupational therapy modalities and techniques within a biomechanical approach include splinting and physical agent modalities. These are all essential in the treatment of clients with hand conditions, but should not be applied without careful consideration of the person and their occupational roles, needs and goals. A minimum requirement for meaningful intervention is facilitating the realisation of clients' priorities for activity participation.

According to Cooper ${ }^{10}$ the practice of OBHT has at its core a client-centred and holistic approach that includes and considers the psychological aspects that may be impacted by a hand injury. In addition, Colaianni and Provident" point out that an OBHT approach facilitates holism. The therapist - client relationship is essential in establishing the occupational goals, through interview, observations and assessments such as the Canadian Occupational Performance Measure (COPM) ${ }^{4,8}$.

\section{THE SOUTH AFRICAN CONTEXT}

Occupational therapists in South Africa practice hand therapy in a variety of settings. These settings include hand therapy services in private practice and public health facilities that range from community health centres to (specialist) tertiary hospitals. The diverse nature of the physical, social and attitudinal environments ${ }^{12}$ in which we practice, and the patient population served, restrict potential for the provision of routine occupational therapy services. In some settings poor implementation of health policies, intended for improved service delivery still continues ${ }^{13}$. The dearth in suitable human resources in health care settings also hinders adequate service delivery ${ }^{13}$. It seems therefore that the South African context imposes barriers to the application of an OBHT approach that is unique to this country's context.

\section{AIM}

This commentary aims to explore some of the barriers internationally, unpack the perceived local barriers and to make recommendations for drafting OBHT guidelines and for future research needs in South Africa.

\section{Barriers to Occupation based hand therapy - internationally}

In order to contextualise the perceived barriers to an OBHT approach in South Africa, we first had to familiarise ourselves with the international barriers. The effectiveness of an OBHT approach is a potential barrier to implementation. Robinson, Brown and O'Brien ${ }^{14}$ confirmed a paucity of evidence for the effectiveness of an occupation-based approach in the field of hand therapy. All evidence published over the past 10 years emanate from so-called developed countries ${ }^{7,8,11,15,16 \text {. Daud }}$ et $\mathrm{al}^{17}$, did however, undertake a randomised controlled trial in Malaysia, which is regarded as a developing country.

They investigated the effectiveness of an OBHT approach and therapeutic exercise (TE) as compared with TE only in the rehabilitation of hand injured clients and reported improved outcomes in the group that received both OBHT and TE ${ }^{17}$.

In addition, the authors reviewed international findings with regards to barriers experienced by occupational therapists aiming to adopt OBHT. Here again, evidence was limited to developed countries with three studies available for review. Colaianni and Provident ${ }^{\prime \prime}$, Golaianni et $\mathrm{al}^{16}$ and Grice ${ }^{1}$ explored the reasons for therapists who do not adopt OBHT in routine hand therapy practice. Both quantitative and qualitative research approaches were included in the search. The findings are outlined in Table $I$.

\section{Table I: Barriers to an Occupation Based Hand Therapy} approach

\begin{tabular}{|c|c|}
\hline Barrier & Reasons given \\
\hline Time $1,11,16$ & $\begin{array}{l}\text { Lack of time was the most commonly cited } \\
\text { reason for not using an occupation-based } \\
\text { approach. Therapists stated that it was often } \\
\text { quicker in busy clinical settings to identify } \\
\text { specific limitations in body function and } \\
\text { structure and then address those, not taking } \\
\text { into account the complexity of the client's } \\
\text { environment. An increase in caseload had } \\
\text { increased the demands on therapists' time. } \\
\text { Golaianni et al. }{ }^{16} \text { reported on the pressure } \\
\text { for productivity, overbooked schedules and } \\
\text { referring doctors sending patients without } \\
\text { prior warning; impacting on therapists' time. }\end{array}$ \\
\hline $\begin{array}{l}\text { Physical work } \\
\text { environment } \\
\text { and available } \\
\text { equipment }{ }^{1,11,16}\end{array}$ & $\begin{array}{l}\text { Restrictions in their physical environment } \\
\text { prevented therapists from using OBHT. } \\
\text { They reported that their practice settings } \\
\text { are often not suited or equipped to adopt } \\
\text { an occupation-based approach, due to lack } \\
\text { of space and/or equipment. A participant in } \\
\text { Golaianni et al's } 16: 183 \text { research of occupation- } \\
\text { based hand therapy stated that: "it [OBHT] } \\
\text { is difficult in an outpatient setting focusing } \\
\text { on the plastic and orthopaedic concerns... } \\
\text { The necessary items to simulate or practice } \\
\text { occupations are not easy to keep or use". }\end{array}$ \\
\hline Reimbursement issues" & $\begin{array}{l}\text { Concerns were expressed that in the } \\
\text { developed country in which Golaianni } \\
\& \text { Provident }{ }^{\prime \prime} \text { investigated the barriers } \\
\text { to OBHT, medical insurance companies } \\
\text { do not pay for an occupation-based } \\
\text { approach. Difficulty in documenting OBHT } \\
\text { outcomes to ensure successful claims for } \\
\text { reimbursement, is reported as an important } \\
\text { factor. }\end{array}$ \\
\hline Treatment protocols $s^{1,11}$ & $\begin{array}{l}\text { The stages of wound healing and restrictions } \\
\text { and/or precautions imposed by the healing } \\
\text { process, for example in flexor tendon } \\
\text { rehabilitation, were reported as barriers to } \\
\text { OBHT. }\end{array}$ \\
\hline $\begin{array}{l}\text { Unfamiliarity } \\
\text { with occupation } \\
\text { based assessment } \\
\text { and treatment } \\
\text { approach } 1,11,16\end{array}$ & $\begin{array}{l}\text { Colaianni \& Provident }{ }^{11} \text {, Golaianni et al }{ }^{16} \text { and } \\
\text { Grice }{ }^{1} \text { reported that therapists were mostly } \\
\text { unfamiliar with an OBHT assessment and } \\
\text { treatment approach. Therapists use what } \\
\text { they are familiar and/or comfortable with and } \\
\text { what is available in their practice settings. }\end{array}$ \\
\hline Therapist preference' & $\begin{array}{l}\text { Even though therapists acknowledged the } \\
\text { benefits of OBHT, Grice' reported that } \\
\text { traditional approaches were still found to } \\
\text { be therapists' preference in routine daily } \\
\text { practice. }\end{array}$ \\
\hline
\end{tabular}




\section{Perceived Barriers to occupation-based hand therapy in the South African context}

In our opinion the South African context varies from that of the developed countries reported on in the literature above. South Africa is reported to face an "unprecedented burden of morbidity and mortality arising from violence and injury" $18: 1011$. "Violence and unintentional injuries" (that often result in hand injury) was the second leading cause of all death and disability-adjusted life years lost in South Africa in $2000^{18}$. In addition, there continues to be health inequities, despite rigorous work towards the right to health for all'3. It can therefore be argued that due to these contextual considerations, hand therapy practice in the South African context is bound to be different to that of developed countries. It is important to consider the contextual barriers faced in this (the local) context. Even though the authors have not formally investigated the barriers to OBHT in South Africa, from practice experience, both internationally and nationally in both private and public health care settings, we propose the following common and additional barriers to those experienced internationally (see Table 2).

\section{Guidelines for an OBHT approach:}

Amini ${ }^{7,8}$, Grice' and Golaianni and Provident ${ }^{10}$ have suggested several guidelines for the adoption of an OBHT approach in routine daily practice. We reviewed these guidelines taking into consideration our conceptualisation of the perceived barriers to an OBHT approach in South Africa and propose the following guidelines for the South African context:

* The use of existing client-centred assessments, including - but not limited to - patient-rated outcome measures such as the Disabilities of the Arm Shoulder and Hand Questionnaire $(\mathrm{DASH})^{20}$ or the COPM ${ }^{21}$. Therapists should explore the limitations in activity and participation in addition to body function and structure and develop client-centred treatment goals. These assessments should then be used to document the outcome of therapy.

African context

\begin{tabular}{|c|c|}
\hline Perceived barriers & Reason \\
\hline Time & $\begin{array}{l}\text { Similar to the finding reported by authors from developed countries } \\
\text { above, therapists practicing in South Africa are often confronted with } \\
\text { high caseloads and quick turnover of referrals. Medical aid limitations } \\
\text { exist with regards to the amount of time that can be spent per client, } \\
\text { to comply with the rules for billing. } \\
\text { Therapists often do not have prior knowledge of the referral and are } \\
\text { therefore unable to allocate adequate time for an occupation-based } \\
\text { approach to hand therapy. This is further complicated by the fact } \\
\text { that the therapists do not have sufficient time to prepare for therapy } \\
\text { sessions. }\end{array}$ \\
\hline Perceptions from colleagues & $\begin{array}{l}\text { Perceptions regarding the credibility of an OBHT approach are } \\
\text { of concern. We have experienced this from colleagues within } \\
\text { our own profession and from other professions. In busy clinical } \\
\text { settings, colleagues might perceive OBHT as more time consuming } \\
\text { and therefore it wastes time that could have been used for } \\
\text { accommodating additional clients. }\end{array}$ \\
\hline Expectations of doctors & $\begin{array}{l}\text { Doctors, often the first contact for the client and source of referral } \\
\text { to the occupational therapists, in some instances dictate the } \\
\text { length and nature of overall occupational therapy intervention. } \\
\text { Expectations from the doctor, imposed on the client, might be } \\
\text { that once body function and structure goals have been reached, } \\
\text { the client is discharged from treatment and in effect occupational } \\
\text { therapy. In many such instances there might be persisting problems in } \\
\text { occupational performance, which could have been addressed by an } \\
\text { OBHT approach over a longer time period. }\end{array}$ \\
\hline Client follow up & $\begin{array}{l}\text { There are multiple complications with regards to client follow up. } \\
\text { In South Africa follow-up appointments are often restricted by } \\
\text { limitations in transport and financial constraints on the client. } \\
\text { Due to the nature of national health departments and the different } \\
\text { levels of care }{ }^{19} \text {, there are no established referral pathways, have often } \\
\text { not been established or are ineffective. This could result in the client } \\
\text { not being followed up. }\end{array}$ \\
\hline Physical environment & $\begin{array}{l}\text { Lack of space and resources is a reality in many settings, a shared } \\
\text { barrier with developed countries }{ }^{15} \text {. In the private sector therapists } \\
\text { pay for treatment space, and often are unable to afford adequate } \\
\text { space to house simulated environments. The same goes for many } \\
\text { government settings where space is often shared with other } \\
\text { members of the multi-disciplinary team. }\end{array}$ \\
\hline Knowledge & $\begin{array}{l}\text { We postulate that therapists in South Africa, like our counterparts in } \\
\text { the developed countries, may be unaware of the body of knowledge } \\
\text { on the assessment and treatment approaches reflecting OBHT. There } \\
\text { is limited access to resources and academic information. } \\
\text { An additional perceived barrier to OBHT is the lack of understanding } \\
\text { and /or appreciation of the occupationally and culturally varied context } \\
\text { within which we practice. }\end{array}$ \\
\hline Language & $\begin{array}{l}\text { The authors believe that language barriers in South Africa could be a } \\
\text { contributing barrier to an OBHT approach, as communication is key } \\
\text { to a client- centred, occupation-based approach. }\end{array}$ \\
\hline
\end{tabular}

* Therapists are encouraged to communicate to the best of their ability, and effectively. Communicate clearly what clients can expect during OBHT. Foster conversation, interaction and communication between the therapist and the client to avoid making assumptions about the impact of their hand injury on their occupational performance ${ }^{7}$. In the context of client-centred goals, the therapists must ensure that the client contributes meaningfully to prioritising treatment goals. An effort must also be made to apply appropriate adult learning principles?.

* OBHT must include sound knowledge and understanding of the requirements of an activity, task or occupation. Activity analysis contributes to successfully facilitating the transition between the clinical setting (therapy practice) and the client's real-life environment. Meaningful occupations can be used to motivate clients to integrate improvements in body structure and functions at home 9 . In addition, as described by $\mathrm{Amini}^{8}$, occupations can be used to assist a client to return to psychosocial well-being while they await improvement in the affected body function or structure.

* Therapists should continue to employ biomechanical approaches, but make a transition to include and occupationbased approach in routine 
hand therapy practice ${ }^{8}$. An OBHT approach should not be separated from biomechanical principles. Amini ${ }^{8}$ provides a case example of a 54 year old self-employed plumber with a zone II flexor tendon injury to his dominant little finger. Through the use of the COPM the identified problems were prioritised by the client and were formulated in the following treatment goals: I) Improvement in body function and structure (range of motion and muscle strength) of the affected finger and 2) full independence in activities of daily living (ADL) one month following surgery ${ }^{8}$. Therapists simultaneously addressed the limitation in activity and participation and body function and structure. Body function and structure goals were addressed by attending to the wound, addressing oedema, introducing the flexor tendon regimen and splinting ${ }^{8}$. Limitations in activity and participation were addressed by modification of the activity and the use of adaptive skills and equipment to ensure independence in bathing, toilet hygiene and dressing ${ }^{8}$.

* Jack and Estes ${ }^{4}$ propose that therapists should not wait until biomechanical approaches fail before introducing an occupation-based approach in intervention. They suggest that these approaches should occur simultaneously as was proposed above $^{3}$. The case study in their article describes how initially the client goals were set within a biomechanical frame of reference without using tools such as the COPM or the DASH ${ }^{4}$. The body function and structure limitations of this client persisted and functional goals important to the client were not documented ${ }^{4}$. It was only when a shift was made to an OBHT approach that improvement was noted. Through thorough consideration of the client's activity and participation needs and goals the clients' motivation improved and significant functional progress was documented $^{4}$

\section{RECOMMENDATIONS}

We recommend the following for education, research and practice.

\section{Education:}

* Undergraduate and post-graduate teaching in the field of hand therapy should be framed by an occupation-based approach.

* Bodies such as the South African Society of Hand Therapists and the Occupational Therapy Association of South Africa should be encouraged to offer courses towards the advancement of OBHT in South Africa.

\section{Research:}

* The perceived barriers to an OBHT approach are often experienced as not fully under the control of therapists. The authors suggest cost effectiveness studies to convince management and medical aids of the benefits of OBHT.

* There is a need for qualitative research for investigating OBHT to (i) demonstrate the validity of such an approach towards enhancing quality of life and (ii) explore the relationship between physical and psychological recovery.

* Documenting occupation as a treatment modality, using appropriate occupation-based outcome measures would be useful in gathering evidence for quantitative research activities on the effectiveness of occupation-based hand therapy.

\section{Practice:}

* Recording outcomes that embody an OBHT approach in routine daily practice is essential.

* Using language in daily encounters with colleagues to reflect the occupational goals of clients and to not limit the conversation/ reporting to body function and structure.

* Therapists wanting to adopt an occupation-based hand therapy approach should seek mentorship and collegial support. This would enrich the knowledge and expertise available on this topic in South Africa.

\section{CONCLUSION}

Practicing OBHT in South Africa is challenging. A strong argument can be made for the use of occupation-based interventions in routine daily practice and research in this field. The domains of activity and participation are at the core of occupational therapy services, and it is therefore our responsibility to ensure that hand therapy practice is occupation-based. The use of an occupation-based approach fosters an understanding and appreciation of the impact of the hand injury on the person, their activity and participation needs and goals, within their environment. We acknowledge the barriers faced by occupational therapists in both public and private sectors but also accept that it is therapists' responsibility to bridge the gap between the biomechanical frame of reference and a holistic occupation- based approach. We have begun to speculate on barriers that may exist in South Africa and suggested initial guidelines for an $\mathrm{OBHT}$ approach and made recommendations.

\section{REFERENCES}

I. Grice KO. The use of occupation-based assessments and intervention in the hand therapy setting. A survey. Journal of Hand Therapy, 20I5; 28(3): 300-306

2. South African Society of Hand Therapists. Hand Therapy. 2015; Available at: http://www.sasht.org.za/. (Accessed 23 September 20I5).

3. Trombly CA. Occupation: Purposefulness and meaningfulness as therapeutic mechanisms. American Journal of Occupational Therapy, 1995; 49(10): 960-972.

4. Jack J, Estes RI. Documenting progress: Hand therapy treatment shift from biomechanical to occupational adaptation. American Journal of Occupational Therapy, 2010; 64(I): 82-87.

5. World Health Organization. ICF Checklist. Geneva: World Health Organization, 200I.

6. Geyh S, Peter C, Müller R, Bickenbach JE, Kostanjsek N, Üstün BT. The personal factors of the International Classification of Functioning, Disability and Health in the literature-a systematic review and content analysis. Disability and Rehabilitation, 20II; 33(I3-I4): I089-II02.

7. Amini D. Occupation-based hand therapy and the occupational therapy practice framework. OT Practice, 2008; 3:17-2I.

8. Amini D. Renaissance occupational therapy and occupation-based hand therapy. OT Practice, 2004; 9(3): II-I5.

9. De Klerk S, Buchanan $\mathrm{H}$, Pretorius B. Occupational therapy hand assessment practices: Cause for concern? South African Journal of Occupational Therapy, 2015; 45(2): 43-50.

10. Cooper C. Narratives in hand therapy. Journal of Hand Therapy, 20II; 24(2): I32-I39.

II. Colaianni D, Provident I. The benefits of and challenges to the use of occupation in hand therapy. Occupational Therapy in Health Care, 2010; 24(2): 130-I46.

12. Schneidert M, Hurst R, Miller J, Üstün B. The role of environment in the International Classification of Functioning, Disability and Health (ICF). Disability and Rehabilitation, 2003; 25(I I- I 2): 588-595.

13. Coovadia H, Jewkes R, Barron P, Sanders D, Mclntyre D. The health and health system of South Africa: historical roots of current public health challenges. The Lancet, 2009; 374(9692): 817-834.

14. Robinson LS, Brown T, O'Brien L. Embracing an occupational perspective: Occupation-based interventions in hand therapy practice. Australian Occupational Therapy Journal, 2016; 63(4): 293-296.

15. Amini D. Occupational therapy interventions for work-related injuries and conditions of the forearm, wrist, and hand: A systematic review. American Journal of Occupational Therapy, 20I I; 65(I): 29-36.

16. Colaianni DJ, Provident I, DiBartola LM, Wheeler S. A phenomenology of occupation-based hand therapy. Australian Occupational Therapy Journal, 2015; 62(3): I77-186.

17. Daud AZC, Yau MK, Barnett F, Judd J, Jones RE, Nawawi RFM. Integration of Occupation Based Intervention in Hand Injury Rehabilitation: A Randomized Controlled Trial. Journal of Hand Therapy, 2016; 29(I): 30-40.

18. Seedat M, Van Niekerk A, Jewkes R, Suffla S, Ratele K. Violence and 
injuries in South Africa: prioritising an agenda for prevention. The Lancet, 2009; 374(9694): 1011-1022.

19. National Planning Commission. National Development Plan Vision 2030. 2013.

20. Hudak P, Amadio P, Bombardier C. DASH Questionnaire. 2013; Available at: http://www.dash.iwh.on.ca/, 1996.

2I. Law M, Baptiste S, McColl M, Opzoomer A, Polatajko H, Pollock $\mathrm{N}$. The Canadian occupational performance measure: an outcome measure for occupational therapy. Canadian Journal of Occupational Therapy, 1990; 57(2): 82-87. 